\title{
Strategi Pengembangan Desa Wisata Berbasis Wisata Alam \& Budaya Sebagai Media Promosi Desa Sangiang
}

\author{
*Tri Putri Rahmatillah', Osy Insyan 1, Nurafifah 2, Fariz Primadi Hirsan' \\ ${ }^{1}$ Perencanaan Wilayah dan Kota, Fakultas Teknik,Universitas Muhammadiyah Mataram \\ ${ }^{2}$ IImu Administrasi Bisnis, Fakultas IImu Sosial dan Politik,Universitas Muhammadiyah Mataram \\ *Email: triputri0911@gmail.com
}

\section{INFO ARTIKEL}

Riwayat Artikel:

Diterima:17-07-2019

Disetujui: 27-11-2019

\section{Kata Kunci:}

Desa Wisata

Strategi

Promosi

SWOT

\begin{abstract}
ABSTRAK
Abstrak:Pengembangan desa wisata berdasarkan budaya dan potensi alam berkembang pesat di Indonesia dan memberikan pemasukan besar bagi pembangunan. Salah satu desa yang berpotensi dikembangkan sebagai desa wisata adalah Desa Sangiang, Kecamatan Wera, Kabupaten Bima, Provinsi Nusa Tenggara Barat. Penelitian ini bertujuan untuk mencari tahu mengenai permasalahan mendasar terkait pengembangan desa wisata alam dan budaya di Desa Sangiang serta upaya mengatasi permasalahan tersebut, mencari tahu sejauh mana peranan dari masyarakat Desa Sangiang dalam mendukung pengembangan desa wisata Sangiang dan pada akhirnya dari penelitian ini diharapkan dapat menemukan strategi pengembangan desa wisata berbasis wisata alam dan budaya sebagai media promosi Desa Sangiang. Adapun metode yang digunakan dalam analisis adalah deskriptif kualitatif dan analisis SWOT. Dari penelitian ini ditemukan bahwa permasalahan dasar yang menghambat pengembangan wisata di Desa Sangiang berupa pelayanan sarana dan prasarana yang belum maksimal. Di sisi lain kekuatan yang dimiliki Desa ini dalam mengembangkan wisata adalah masyarakat setempat sudah ikut berperan dalam pengembangan desa wisata. Setelah dilakukan analisis, strategi yang dapat dilakukan dalam mengembangkan Desa Wisata Sangiang yaitu peningkatan kualitas pelayanan sarana prasarana, menjaga dan melestarikan potensi wisata, meningkatkan promosi wisata, dan mengemas seluruh potensi wisata menjadi kesatuan paket wisata.
\end{abstract}

\begin{abstract}
The development of tourism village based on the culture and potential of natural growth in Indonesia and provide a substantial income for development. One of the villages that have been potentially developed as a tourist village is Sangiang Village, Wera Subdistrict, Bima Regency, West Nusa Tenggara province. This research aims to find out about the fundamental problems related to the development of natural and cultural tourism village in Sangiang Village as well as efforts to overcome the problem, to find out the extent of the role of the community Sangiang village in Support the development of Sangiang Tourism village and in the end of this research is expected to find a strategy of tourism Village development based on nature and cultural tourism as a promotional media Sangiang village. As for the methods used in the analysis is a qualitative descriptive, and SWOT analysis. This research found that the basic problem that inhibits the development of tourism in Sangiang village in the form of service and infrastructure is not maximized. On the other hand, the strength of this village in developing tourism in the local community has been instrumental in the development of tourism villages. After analysis, the strategy that can be done in developing Sangiang tourism village is the improvement of the quality of infrastructure services, preserve and preserve the potential of tourism, increase travel promotion, and package all potential Tour becomes a unity tour package.
\end{abstract}

\section{A. LATAR BELAKANG}

Sektor pariwisata menjadi sektor penting dalam memberikan pemasukan serta sumber defisit bagi pembangunan disuatu daerah. Pariwisata yang merupakan suatu kegiatan pergerakan manusia dalam melakukan perjalanan yang bersifat sementara, ke suatu tempat diluar daerah tempat tinggalnya dengan tujuan tanpa bermaksud mencari nafkah (Gunn, Clare A: 2002). Saat ini pariwisata berkembang pesat dengan berbagai jenis pilihannya, diantaranya adalah pariwisata minat khusus. Wisata minat khusus adalah bentuk perjalanan wisata, dimana wisatawan mengunjungi suatu tempat karena memiliki minat khusus dari objek atau kegiatan di daerah tujuan wisata (Weiler Hall, 1992) . Para wisatawan yang cenderung berwisata berdasarkan minat khusus ini biasanya dilakukan dengan beberap alas an yaitu menghargai alam, mencari tahu tentang budaya, sejarah, lingkungan, adat istiadat serta tradisi yang berkembang.

Desa wisata yaitu desa yang dikembangkan dengan memanfaatkan unsur-unsur atau petensi yang ada pada desa serta masyarakatnya sebagai produk atau atribut wisata, sehingga menjadikan rangkaian pariwisata menjadi aktivitas yang terpadu dan bertema (Putra, 2006). Dalam hal ini, salah satu desa yang berpotensi 
untuk dikembangkan sebagai desa wisata berbasis wisata budaya dan alam adalah Desa Sangiang. Dengan melihat prospek pariwisata kedepannya yang akan sangat menjanjikan dalam memberikan kontribusi yang besar dalam pembangunan daerah.

Desa Sangiang adalah desa yang secara administrasi berada di Kecamatan Wera, Kabupaten Bima, Provinsi Nusa Tenggara Barat, yang terkenal dengan adanya Gunung Sangiang yang masih aktif pada wilayah batas administrasinya. Desa Sangiang memiliki berbagai potensi objek wisata dan budaya yang dapat menarik minat wisatawan untuk berkunjung. Adapun berbagai potensi wisata yang dapat dikembangkan di Desa Sangiang yaitu terdapatnya Gunung Api Sangiang, pantai serta padang savana dibagian selatan Gunung Sangiang, sumber air panas belerang di Pulau Sangiang, ragam budaya seperti budaya menenun yang dilakukan oleh setiap masyarakat dengan bahan kapas yang diperoleh dari hasil panen warga lokal, karombo wera (goa wera) sebagai wisata sejarah, atraksi pembuatan kapal, parade perahu layar, pembuatan dodol Wera yang diolah secara tradisional serta terdapatnya festival Sangiang Api setiap tahunnya.

Oleh karena itu, dengan dilakukan pengembangan potensi wisata lebih lanjut di Desa Sangiang, diharapkan akan dapat menarik banyak wisatawan untuk mengunjungi dan lebih mengenal kawasan wisata Desa Sangiang. Namun, disisi lain akan timbul berbagai persoalan dalam mengembangkan desa wisata Sangiang, diantaranya yaitu kesiapan dari masyarakat sebagai objek dari wisata, permasalahan sarana dan prasarana pendukung, bentuk kemasan dari potensi daya tarik wisata alam dan budaya, kenyamanan dari wisatawan yang datang berkunjung dan sebagainya. Maka, penelitian ini bertujuan untuk mengembangkan Desa Sangiang sebagai kawasan desa wisata alam dan budaya dengan mengemas berbagai potensi yang ada, sehingga menjadi media promosi bagi Desa Sangiang sebagai objek wisata.

Penelitian ini bertujuan untuk mencari tahu mengenai permasalahan mendasar terkait pengembangan desa wisata alam dan budaya di Desa Sangiang serta upaya mengatasi permasalahan tersebut, mencari tahu sejauh mana peranan dari masyarakat Desa Sangiang dalam mendukung pengembangan desa wisata Sangiang dan pada akhirnya dari penelitian ini diharapkan dapat menemukan strategi pengembangan desa wisata berbasis wisata alam dan budaya sebagai media promosi Desa Sangiang.

\section{B. METODE PENELITIAN}

Jenis penelitian dilakukan secara deskriptif kualitatif yaitu menafsirkan keadaan yang sebenarnya terjadi dan menguraikan data yang bersangkutan dengan situasi maupun sikap atau pandangan yang ada di masyarakat.
Pada penelitian ini, yang dijadikan subjek dalam penelitian adalah pemerintah desa setempat dan masyarakat Desa Sangiang. Oleh karena itu, objek dari penelitian berada di Desa Sangiang.

Adapun teknik pengumpulan data yang dilakukan dalam penelitian ini yaitu teknik pengumpulan data sekunder yaitu dengan melakukan kajian kepustakaan dan survey instansi serta pengumpulan data primer yaitu pengumpulan data yang dilakukan dengan turun lapangan langsung ke Desa Sangiang dan melakukan wawancara serta dokumentasi. Sedangkan teknik analisis yang digunakan adalah dengan metode analisis deskriptif kualitatif dan teknik analisis dengan metode analisis SWOT (strength, weakness, opportunity, treath).

\section{HASIL DAN PEMBAHASAN}

\section{Identifikasi Komponen Kepariwisataan serta Permasalahan}

Dalam hal ini, identifikasi komponen kepariwisataan yaitu dengan mengkaji potensi pariwisata atau atraksi, aksesibilitas, amenitas dan akomodasi yang ada di Desa Sangiang. Hal ini dikarenakan dalam mengembangkan destinasi wisata yang unggul, sebelum wisata tersebut diperkenalkan dan dipromosikan, terlebih dahulu mengenali 4 aspek utama tersebut yaitu attraction, accessibility, amenity, dan ancilliary (menurut Cooper sebagaimana dikutip oleh Prof. Dr. Ir. I Gede Pitana dalam seminar cooperation in the development of education and tourism in global era, 2012). Adapun hasil identifikasi dapat dilihat pada tabel berikut:

\section{Tabel 1}

\section{IDENTIFIKASI KOMPONEN KEPARIWISATAAN}

\begin{tabular}{|c|c|c|}
\hline No & Variabel & Hasil Identifikasi \\
\hline 1 & Atraksi & $\begin{array}{l}\text { - Terdapat gunung api Sangiang } \\
\text { - Karombo Wera (Goa Wera) sebagai } \\
\text { peninggalan sejarah } \\
\text { - Kain tenun khas Sangiang } \\
\text { - Pembuatan dodol Wera secara } \\
\text { tradisional } \\
\text { - Makanan khas Desa Sangiang } \\
\text { seperti kalempe } \\
\text { - Atraksi pembuatan kapal dari } \\
\text { masyarakat yang unik } \\
\text { - Parade perahu layar } \\
\text { - Sumber air panas belerang di Pulau } \\
\text { Sangiang } \\
\text { - Benda-benda kuno peninggalan } \\
\text { sejarah ditemukan di Pulau } \\
\text { Sangiang seperti gong, kendi, } \\
\text { wajan, batu sumpah yang menjadi } \\
\text { sejarah antara Kerajaan Bima dan } \\
\text { Moyang Sangiang } \\
\text { - Pantai yang jernih di Pulau } \\
\text { Sangiang } \\
\text { - Adat masyarakat yang masih kental } \\
\text { berupa tarian, gele, hadra, } \\
\text { nyanyian bima, biola bima } \\
\text { - Festival Api Sangiang yang tiap } \\
\text { tahunnya menyajikan parade } \\
\text { perahu layar, lomba perahu layar, } \\
\text { jelajah Pulau Sangiang, berburu }\end{array}$ \\
\hline
\end{tabular}




\begin{tabular}{cll}
\hline Aksesibili & $\begin{array}{l}\text { massal di Pulau Sangiang, Lomba } \\
\text { dayung sampan, pawai budaya, } \\
\text { kuliner dan sebagainya } \\
\text { Akses jalan cukup memadai dengan } \\
\text { kondisi yang sudah teraspal dan } \\
\text { belum terdapat rambu-rambu } \\
\text { petunjuk jalan. }\end{array}$ \\
3 & Amenitas & $\begin{array}{l}\text { Sudah terdapat kios-kios kecil, mini } \\
\text { market serta warung makan } \\
\text { Tempat penginapan atau home stay } \\
\text { belum tersedia } \\
\text { Sudah terdapat kodarwis }\end{array}$ \\
\hline
\end{tabular}
Sumber: Hasil Survey 2019

Adapun permasalahan yang dialami oleh Desa Sangiang adalah sarana dan prasarana penunjang pariwisata masih kurang seperti ketersediaannya tempat sampah, MCK umum, tempat penginapan (home stay), masih kurangnya pengelolaan pariwisata seperti pemandu wisata bagi wisatawan luar domestik.

Oleh karena itu, upaya yang dapat dilakukan adalah dengan memberikan pelayanan yang maksimal bagi wisatawan seperti peningkatan kualitas sarana dan prasarana pendukung pariwisata. Keberadaan kodarwis lebih dimaksimalkan lagi agar tidak hanya aktif disaat kegiatan tertentu, sehingga dapat terus berjalan kelembagaannya dan dapat aktif menjadi pemandu bagi wisatawan.

\section{Peranan Masyarakat}

Dalam kegiatan wisata di Desa Sangiang, masyarakat sudah ikut berperan, hal ini ditunjukkan dengan masyarakat yang menerima dengan baik kedatangan wisatawan domestik maupun luar domestik. Masyarakat ikut andil dalam kegiatan wisata seperti dalam kegiatan Festival Sangiang Api yang diadakan tiap tahunnya, masyarakat berperan aktif dalam memeriahkan festival. Seperti halnya ikut dalam berbagai kegiatan yang diadakan dalam festival, melakukan kegiatan wirausaha yaitu mendagangkan hasil tenunan, kuliner dan sebagainya. Hal ini merupakan salah satu upaya dalam memanfaatkan wisata, yaitu ikut berperan dalam kegiatan wisata sehingga diharapkan dapat meningkatkan perekonomian masyarakat setempat.

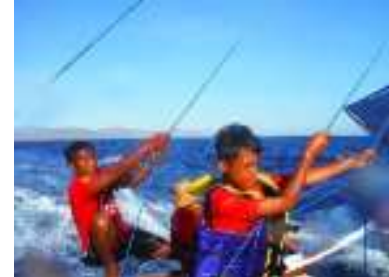

Ganbar 1. Kegiatan Masyarakat dalam Lomba Perahu Layar

Selain itu, dari hasil pengamatan yang dilakukan, masyarakat terbuka dengan kedatangan wisatawan dari luar maupun dalam negeri. Anak-anak Desa Sangiang akan dengan senang mendatangi para turis yang berdatangan dan berbincang dengan mereka. Adapun dalam kegiatan budaya menenun, masyarakat setempat juga akan menerima dengan baik apabila wisatawan yang ingin melihat, bertanya ataupun mencoba langsung pengalaman dalam menenun.

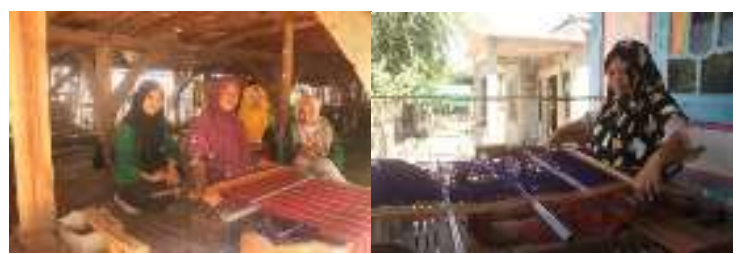

Gambar 2. Budaya Menenun Masyarakat Sangiang

\section{Strategi Pengembangan Desa Wisata}

Pariwisata merupakan salah satu sektor utama penggerak ekonomi di Desa Sangiang. Oleh karena itu, dalam penentuan strategi pengembangan Desa Sangiang sebagai desa wisata berbasis wisata alam dan budaya sebagai media promosi desa, dilakukan dengan menggunakan analisis SWOT (Strength, Weakness, Opportunity, Threat). Kondisi dari dalam desa yang bersifat positif (kekuatan) dan sifat negatif (kelemahan) dilihat sebagai faktor internal, sedangkan faktor-faktor yang berasal dari luar berupa ancaman dan peluang disebut faktor eksternal. Berikut hasil dari penelitian yang telah dilakukan yang disajikan dalam tabel IFAS dan EFAS:

\section{1.) Faktor Internal}

Tabel 2

FAKTOR STRATEGIS INTERNAL (IFAS)

\begin{tabular}{|c|c|c|c|c|c|}
\hline No & Faktor Strategis Internal (IFAS) & Bobot & Rating & Skor & Kode \\
\hline & Kekuatan & & & & \\
\hline 1 & $\begin{array}{l}\text { Memiliki daya tarik wisata yang khas yaitu dari alam dan } \\
\text { masyarakatnya }\end{array}$ & 0,15 & 4 & 0,6 & S1 \\
\hline 2 & Memiliki budaya dan sejarah yang unik & 0,15 & 4 & 0,6 & S2 \\
\hline 3 & $\begin{array}{l}\text { Adanya berbagai jenis wisata seperti gunung sangiang, } \\
\text { karombo wera, pantai, atraksi pembuatan kapal, budaya } \\
\text { menenun, festival sangiang api dan sebagainya. }\end{array}$ & 0,15 & 4 & 0,6 & $\mathrm{~S}_{3}$ \\
\hline 4 & Adanya kesenian serta kerajinan masyarakat & 0,09 & 3 & 0,27 & S4 \\
\hline 5 & Adanya makanan khas & 0,07 & 2 & 0,14 & $\mathrm{~S}_{5}$ \\
\hline
\end{tabular}




\begin{tabular}{|c|c|c|c|c|c|}
\hline 6 & Sikap masyarakat yang ramah & 0,08 & 2 & 0,16 & S6 \\
\hline & Sub Total & $\mathbf{0 , 6 9}$ & & $\mathbf{2 , 3 7}$ & \\
\hline \multicolumn{6}{|c|}{ Kelemahan } \\
\hline 1 & $\begin{array}{l}\text { Sarana dan Prasarana penunjang desa wisata yang kurang } \\
\text { seperti penginapan, tempat sampah, MCK umum, petunjuk } \\
\text { jalan dan sebagainya }\end{array}$ & 0,15 & 1 & 0,15 & W1 \\
\hline 2 & SDM pengelola desa wisata yang masih kurang & 0,07 & 3 & 0,21 & W2 \\
\hline 3 & Masih kurangnya promosi dan pemasaran desa wisata & 0,09 & 2 & 0,18 & W3 \\
\hline & Sub Total & $\mathbf{0 , 3 1}$ & & $\mathbf{0 , 5 4}$ & \\
\hline & Total & $\mathbf{1 , 0 0}$ & & 2,91 & \\
\hline
\end{tabular}

2.) Faktor Eksternal

Tabel 3

FAKTOR STRATEGIS EKSTERNAL (EFAS)

\begin{tabular}{|c|c|c|c|c|c|}
\hline No & Faktor Strategis Eksternal (EFAS) & Bobot & Rating & Skor & Kode \\
\hline \multicolumn{6}{|c|}{ Peluang } \\
\hline 1 & Belum adanya desa wisata di Kecamatan Wera & 0,15 & 4 & 0,6 & O1 \\
\hline 2 & $\begin{array}{l}\text { Peruntukan pariwisata (karombo wera) berdasarkan RTRW } \\
\text { Kabupaten Bima }\end{array}$ & 0,09 & 3 & 0,27 & $\mathrm{O} 2$ \\
\hline 3 & $\begin{array}{l}\text { Wisatawan luar domestik yang selalu datang } 2 \text { kali tiap satu } \\
\text { bulan }\end{array}$ & 0,13 & 3 & 0,39 & O3 \\
\hline 4 & Sudah ada akses menuju desa wisata & 0,15 & 4 & 0,6 & $\mathrm{O} 4$ \\
\hline 5 & Dukungan dari pemerintah daerah & 0,15 & 4 & 0,6 & $\mathrm{O} 5$ \\
\hline & Sub Total & $\mathbf{0 , 6 7}$ & & 2,46 & \\
\hline \multicolumn{6}{|c|}{ Ancaman } \\
\hline 1 & $\begin{array}{l}\text { Bencana alam gunung meletus (gunung sangiang yang masih } \\
\text { aktif) }\end{array}$ & 0,08 & 3 & 0,24 & T1 \\
\hline 2 & $\begin{array}{l}\text { Isu-isu media mengenai konflik yang terjadi di Kabupaten } \\
\text { Bima yaitu perkelahian antar desa }\end{array}$ & 0,08 & 3 & 0,24 & $\mathrm{~T} 2$ \\
\hline 3 & $\begin{array}{l}\text { Pandangan masyarakat luar yang menganggap masyarakat } \\
\text { Wera keras dan mempunyai ego yang tinggi }\end{array}$ & 0,09 & 2 & 0,18 & T3 \\
\hline 4 & Masuknya budaya asing terhadap budaya masyarakat & 0,08 & 3 & 0,24 & $\mathrm{~T} 4$ \\
\hline & $\begin{array}{l}\text { Sub Total } \\
\end{array}$ & $\mathbf{0 , 3 3}$ & & $\mathbf{0 , 9}$ & \\
\hline & Total & $\mathbf{1 , 0 0}$ & & $\mathbf{3 , 3 6}$ & \\
\hline
\end{tabular}

Untuk mengetahui strategi yang harus dilakukan dalam pengembangan desa wisata Sangiang, perlu dibuat matriks space berdasarkan tabel IFAS dan EFAS berikut:

- Kekuatan (Strength) - Kelemahan (Weakness)

$$
=2,37-0,54=1,83
$$

- Peluang (Opportunity) - Ancaman (Treath) = $2,46-0,9=1,56$

Berdasarkan hasil analisis SWOT, menunjukkan bahwa dalam mendukung pengembangan desa wisata Sangiang, maka strategi yang perlu dilakukan adalah strategi S - O (Strength - Opportunity) yaitu strategi yang memanfaatkan kekuatan yang dimiliki oleh Desa Sangiang untuk meraih peluang. Berikut alternatif strategi yang dapat dirumuskan berdasarkan analisis SWOT.

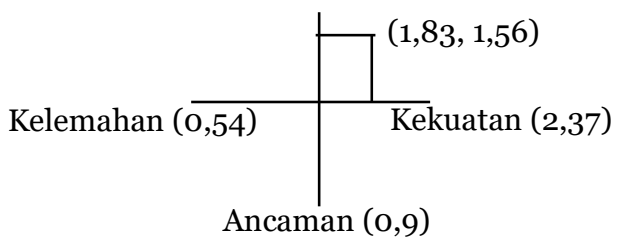

Gambar 3. Matriks Space

Tabel 4

MATRIKS STRATEGI PENGEMBANGAN DESA WISATA SANGIANG

\begin{tabular}{|c|c|c|c|c|c|}
\hline No & Strategi & Kode Pembobotan & Nilai & Prioritas & Ket \\
\hline 1 & $\begin{array}{l}\text { Mengemas seluruh potensi wisata menjadi satu } \\
\text { kesatuan paket wisata dengan pelayanan yang } \\
\text { maksimal dan dukungan dari pemerintah daerah }\end{array}$ & $\begin{array}{l}\mathrm{S}_{1}+\mathrm{S}_{2}+\mathrm{S}_{3}+\mathrm{S}_{4}+\mathrm{S}_{5}+\mathrm{O}_{1}+\mathrm{O} \\
2+\mathrm{O}_{3}+\mathrm{O}_{4}+\mathrm{O}_{5}\end{array}$ & 4,67 & 1 & $\mathrm{~S}-\mathrm{O}$ \\
\hline 2 & $\begin{array}{l}\text { Menjaga serta melestarikan potensi dari wisata } \\
\text { alam dan budava dalam pengendalian isu-isu }\end{array}$ & $\begin{array}{l}\mathrm{S} 1+\mathrm{S}_{2}+\mathrm{S}_{3}+\mathrm{S} 6+\mathrm{T} 2+\mathrm{T}_{3}+ \\
\mathrm{T} 4\end{array}$ & 2,62 & 3 & S-T \\
\hline
\end{tabular}


negatif

3 Meningkatkan promosi desa wisata, kualitas SDM pengelola wisata, serta sarana dan prasarana penunjang pariwisata

$\mathrm{W} 1+\mathrm{W}_{2}+\mathrm{W}_{3}+\mathrm{O}_{1}+\mathrm{O}_{2}+$ $\mathrm{O}_{3}+\mathrm{O}_{4}+\mathrm{O}_{5}$

$\mathrm{W} 1+\mathrm{W} 2+\mathrm{T} 2+\mathrm{T}_{3}+\mathrm{T}_{4}$
3,00

1,02
2

$\mathrm{W}-\mathrm{O}$

W-T
1. Mengemas seluruh potensi wisata menjadi satu kesatuan paket wisata dengan pelayanan yang maksimal dan dukungan dari pemerintah daerah

Strategi ini adalah strategi yang memanfaatkan kekuatan yang ada untuk mendapatkan peluang. Daya tarik wisata yang disuguhkan oleh Desa Sangiang berupa keindahan alam, budaya yang berkembang di masyarakat, kegiatan masyarakat, kesenian daerah dapat berpeluang untuk dikembangkan menjadi desa wisata dan dikemas menjadi paket wisata Desa Sangiang. Selain itu, pengembangan wisata ini tidak dapat berjalan dengan sendirinya namun membutuhkan dukungan dari pemerintah daerah setempat.

2. Menjaga serta melestarikan potensi dari wisata alam dan budaya dalam pengendalian isu-isu negatif

Strategi ini adalah startegi dalam meminimalkan ancaman dengan memanfaatkan dan memaksimalkan kekuatan yang ada. Potensi yang disuguhkan oleh Desa Sangiang dijaga dan dilestarikan dengan baik sehingga tanggapan serta kesan dari wisatawan akan baik apabila melihat kelestarian serta keindahan alam yang terjaga. Hal ini guna mengendalikan isu negatif yang berkembang.

3. Meningkatkan promosi desa wisata, kualitas SDM pengelola wisata, serta sarana dan prasarana penunjang pariwisata

Strategi ini adalah strategi dalam mendapatkan peluang dengan meminimalisir kelemahan yang ada. Desa Wisata Sangiang harus sering dipromosikan agar lebih dikenal oleh wisatawan domestik maupun luar domestik. Promosi bisa dilakukan dengan pembuatan booklet atau profil wisata, melalui media elektronik oleh pemerintah daerah, video promosi dan sebagainya. Disamping dilakukannya promosi wisata, kualitas SDM pengelola wisata harus dikembangkan agar dapat menjadi pemandu wisata yang baik bagi wisatawan yang berkunjung, serta sarana dan prasarana penunjang pariwisata yang lebih ditingkatkan kualitasnya.

4.Memaksimalkan kualitas pelayanan pariwisata dalam memberikan kesan positif bagi wisatawan

Strategi ini adalah startegi dalam meminimalisir kelemahan dan ancaman yang ada. Desa wisata tidak akan berkembang dengan baik apabila pelayanan yang diberikan kurang baik. Oleh karena itu, kerjasama antara masyarakat dan pemerintah daerah setempat sangat dibutuhkan dalam menciptakan kualitas pelayanan pariwisata yang baik. Sehingga, dengan adanya pelayanan yang maksimal, akan memberikan kesan positif kepada wisatawan yang datang berkunjung bahwa anggapan yang tersebar diluar tidaklah benar. Para wisatawan yang berkunjung pun dapat puas dengan potensi pariwisata yang disuguhkan oleh Desa Sangiang.

\section{SIMPULAN DAN SARAN}

Berdasarkan hasil analisis dan identifikasi dalam menjawab rumusan masalah, pada Desa Sangiang terdapat permasalahan mendasar berupa pelayanan sarana dan prasarana yang belum maksimal serta keberadaan kodarwis yang harus ditingkatkan lagi. Selain itu, di Desa Sangiang masyarakat setempat sudah ikut berperan dalam pengembangan desa wisata dilihat berdasarkan keterbukaannya dalam menerima wisatawan. Adapun strategi pengembangan Desa Wisata Sangiang yang bertujuan mendukung kegiatan pariwisata Desa Sangiang yaitu peningkatan kualitas pelayanan sarana prasarana, menjaga dan melestarikan potensi wisata, meningkatkan promosi wisata, dan mengemas seluruh potensi wisata menjadi kesatuan paket wisata.

Adapun sarannya yaitu agar berbagai usaha dan strategi dapat berjalan baik maka pemerintah dan masyarakat, serta pihak lain yang ikut terlibat dapat lebih bekerja sama lagi dalam meningkatkan potensi wisata Desa Sangiang sehingga Desa Sangiang menjadi desa wisata yang dapat dikunjungi oleh banyak wisatawan.

\section{UCAPAN TERIMA KASIH}

1. Terima kasih Kementerian Riset, Teknologi, dan Pendidikan Tinggi (Kemeristekdikti) yang telah mendanai penelitian ini.

2. Terima kasih kepada Dosen Pembimbing Fariz Primadi Hirsan.

3. Terima kasih kepada wakil rektor kemahasiswaan Universitas Muhammadiyah Mataram ynag telah memfasilitasi selama proses kegiatan penelitian.

4. Terima kasih kepada teman-teman tim peneliti dan teman-teman yang telah membantu kami selama proses penelitian. 


\section{DAFTAR RUJUKAN}

[1] I Made Adi Dharmawan, I Made Sarjana, and I Dewa Ayu Sri Yudhari, "Strategi Pengembangan Desa Wisata di Desa Belimbing Kecamatan Pupuan Kabupaten Tabanan", Jurnal Agribisnis dan Agrowisata, Vol 3, No. 1, Januari 2014.

[2] Fariz Zakaria and Rima Dewi Suprihardjo,"Konsep Pengembangan Kawasan Desa Wisata di Desa Bandungan Kecamatan Pakong Kabupaten Pamekasan”, Jurnal Teknik POMITS, Vol 3, No. 2, 2014.

[3] Rangkuti, SWOT Analysis, Gramedia, Jakarta, 2009.
[4] Zaenafi Ariani, and Muhammad Nursan, "Strategi Pengembangan Desa Mantar sebagai Kawasan Desa Wisata di Kabupaten Sumbawa Barat”, Jurnal Biologi Tropis, Vol 17, No. 2, Desember 2017

[5] Weiler, B., \& Hall, C. M. Special interest tourism. London: Belhaven Press 1992

[6] Gun, C. A. Tourism Planning (Bassics, Concepts, Cases). New York: Routledge. 2002 